\title{
DEEP PERMAFROST EVOLUTION IN UNSTABLE SLOPES DURING THE HOLOCENE
}

\author{
Julien Seguinot
}

This work was done at the Laboratoire de Géophysique Interne et Tectonophysique in Grenoble, France, between February and June 2008, under the supervision of Laurent Baillet, Stéphane Schwartz and Jean-François Gamond. It is within the scope of a five-month master of sciences internship.

\begin{abstract}
Large alpine landslides dynamics are generally associated with quaternary glacier retreat. Some recent datations demonstrate that several thousand years can separate the slope failure initiation from ice pressure unloading. The current study adress the question if the persitence of deep permafrost could produce this lag time. A model of deep permafrost evolution is developped, including heat diffusion, phase change and a ground surface transfer function. It is numerically implemented by a $1 \mathrm{D}$ finite difference code on the one hand and into a 2D finite element software on the other hand. Model results reveals the great influence of porosity and near-ground processes in permafrost evolution, and illustrates the possible persitence of a permafrost core into the slope.
\end{abstract}

\section{Résumé}

La dynamique des grands mouvements de terrain alpins est souvent associée au retrait des glaciers quaternaires. Des datations récentes ont cependant démontré qu'il pouvait exister plusieurs millers d'années entre la disparition de la glace et l'initiation des instabilités. Cette étude pose la question du rôle éventuel de la persitence d'un pergélisol profond sur ce délai. Un modèle d'évolution de pergélisol est présenté. Il tient compte de la thermique, des changement d'états et d'une fonction de transfert en surface. Des études numériques sur un code aux différences finies $1 D$ et un logiciel aux éléments finis $2 D$ sont menées. Les résultats obtenus montrent l'importance de la porosité et des processus de surface dans l'évolution du pergelisol, et illustrent la persistance possible d'un noyau de pergelisol dans le massif. 


\section{Contents}

1 Introduction

1.1 Slope instability and permafrost . . . 2

1.2 Permafrost modelling . . . . . . . . . . 2

2 Two alpine failure slopes

2.1 Sassenage rockslide events . . . . . . . 3

2.2 Séchilienne active landslide . . . . . . 3

3 Model setup

3.1 Global presentation . . . . . . . . . . . 4

3.2 Deep temperature evolution . . . . . . 6

3.2.1 Temperature diffusion . . . . . 6

3.2.2 Density and porosity . . . . . . 6

3.2.3 Phase changes . . . . . . . . . 6

3.3 Surface effects . . . . . . . . . . . . 7

3.3.1 The thermal offset . . . . . . 7

3.3.2 The n-factors . . . . . . . . 7

3.3.3 The Kudryatsev equation . . . 8

3.3.4 Testing the TTOP model . . . 9

3.4 Air temperature reconstruction . . . . 9

4 1D sensibility tests $\quad 10$

4.1 Numerical implementation . . . . . . . 10

4.2 Choice of parameters . . . . . . . . . 11

4.3 Results . . . . . . . . . . . . . . . . 13

$5 \quad 2$ D modelling experiments $\quad 13$

5.1 Numerical Implementation . . . . . . . 13

5.2 Results . . . . . . . . . . . . . . . 13

6 Discussion

14

6.1 Model variability . . . . . . . . . . . 14

6.2 Side implications . . . . . . . . . . . 15

\section{Appendixes}

The current master thesis was submitted with three appendixes, comprising a set of plates illustrating the sensibility tests of the $1 \mathrm{D}$ model, the Scilab code of the 1D model and a description of usual models of heat transfert with phase change in permafrost modelling. This last document exists in french and english versions.

\section{Introduction}

\subsection{Slope instability and permafrost}

During the quaternary glaciations, ice was a very efficient erosional agent, carving deep, steep-sided, characteristic glacial troughs in the Alps. During the successive deglaciations, the valley sides were affected by a debutressing phenomenon associated with ice pressure unloading after each glacier retreat (Augustinus, 1995; Ballantyne, 2002). This has led to the formation of mechanically weakened, unstable zones that may evolve as large rockslides.

It is most probable that the initiation of a slope failure does not only depends on the local deglaciation pattern but also on the bedrock lithology, the pre-existing fractures, the eventual underground water drainage network and the persistence of deep permafrost. In the French Alps, field investigations were carried out on the Séchilienne and the Sassenage sites and allowed to constrain a relative timing for the slope failure initiation.

The aim of the current study is to address the role of the persistence of deep fossil permafrost on the stabilization of these slopes. Indeed, one can suspect a massif whose fractures are filled with ice to be more coherent than a thawed one. Moreover, freeze-thaw processes potentially occurring during permafrost thawing may be a second reason to initiate the destabilization of the slope. A numerical model of thermal evolution of a deglaciated slope during the Holocene, using paleo-temperature reconstructions is introduced to give estimation of such processes. Focus is made on deep permafrost extent and melting.

\section{$1.2 \quad$ Permafrost modelling}

During the last decades, the modelling of the present distribution of permafrost in polar and mountainous environment as well as past and future evolution of permafrost has been an active research topic. See Harris et al. (2009) for a complete review of recent advances in permafrost modelling and monitoring.

Numerous models focuses on the seasonnal variability of the active (summer thawing) layer (Ro- 
manovsky and Osterkamp, 2000), whose consequences are not only geophysical (Lliboutry, 1965). The evolution of deeper permafrost deals with different time and space scales, but is controlled by the same laws as surface permafrost, and applies to very diverging domains.

Delisle (1998) used 1D transient and 2D stationary models to address the question of existence and persistence of deep permafrost in Northern Germany. He demonstrated the importance of phase change energy transfers in such kind of models. Wegmann et al. (1998) focused on the temperature evolution in a rock-wall associated with progressive glacier retreat, and evidenced the role of moisture content of the rock. Kukkonen and Šafanda (2001) illustrated the effect of slope orientation by introducing ground surface effects (Smith and Riseborough, 1996) in a deep permafrost evolution model.

More recently, the 2003 very hot summer in the Alps demonstrated that permafrost in steep highmountain rock-walls is sensitive to present climate change and associated with alpine rockfall hazard (Gruber and Haeberli, 2007). Noetzli et al. (2007a,b); Noetzli (2008); Noetzli and Gruber (2008) modelled the stationary and transient states of this highmountain permafrost. The current report proposes to study permafrost modelling applied to large landslide of the kind of Sassenage or Séchilienne.

\section{Two alpine failure slopes}

\subsection{Sassenage rockslide events}

The town of Sassenage is located in the Isère valley, a large SE - NW glacial valley separating the two subalpine carbonates massifs of Vercors and Chartreuse. It belongs to the Grenoble agglomeration. Part of the town and one of the main roads to the Vercors massif are built on a talus made of rockfall deposits, some $100-200 \mathrm{~m}$ above the Isère alluvial plain. They are dominated by the steep $\left(45-50^{\circ}\right)$ slope of the Dent du Loup (Vercors, $1425 \mathrm{~m}$ ) mountain, which exhibits the scars from several bed-to-bed detachments (Gamond et al., 2008).

The topography of this failure slope is roughly par- allel to the bedding of massive Urgonian limestones (fig. 1). It is not known if a failure hazard still threaten the bottom of the slope.

Gamond et al. (2008) demonstrated from paleo-soil datations that at least five massive rockfall events happened in a period covering the 15600 to $3940 \mathrm{cal}$. B.P time interval. The Sassenage slope then became unstable shortly after the glacier retreat, which suggest a limited or absent influence of permafrost, but remained strongly active until a recent past.

\subsection{Séchilienne active landslide}

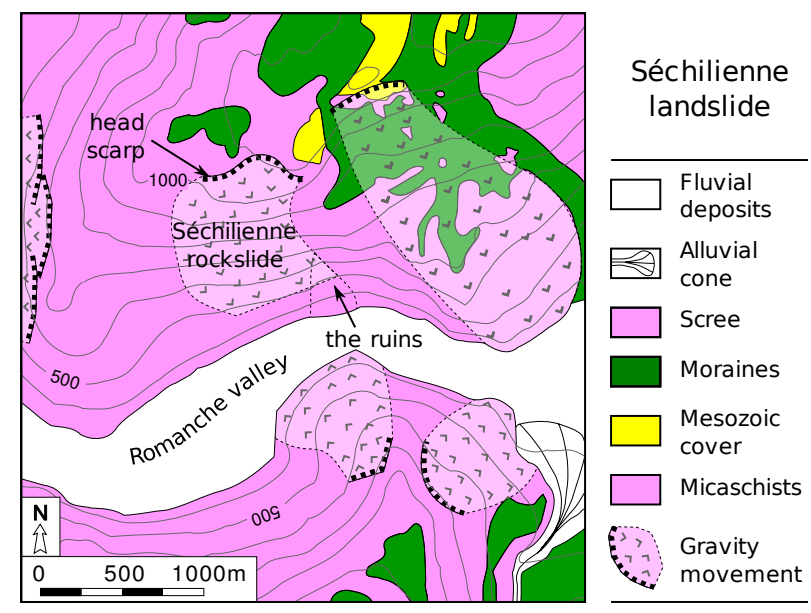

Figure 2: Quaternary map of the Séchilienne area. Modified from le Roux et al. (2009). The Ruins of Séchilienne concerns only a small part of the total unstable zone.

The Séchilienne landslide is located some $20 \mathrm{~km}$ South of Grenoble city in the micaschists of the South Eastern Belledonne extern crystalline massif. The slopes dip towards the lower Romanche valley $(330 \mathrm{~m})$, a very narrow and steep glacial trough dominated by a low topography glacial plateau at $1100 \mathrm{~m}$.

The Séchilienne site is characterized by its current activity and high mass wasting hazard. The active zone is visible in the landscape as a rockfall channel known as the Ruins of Séchilienne (fig. 2). It is however only a small part of the total destabilized zone, which consist in more than $25 \cdot 10^{6} \mathrm{~m}^{3}$ 


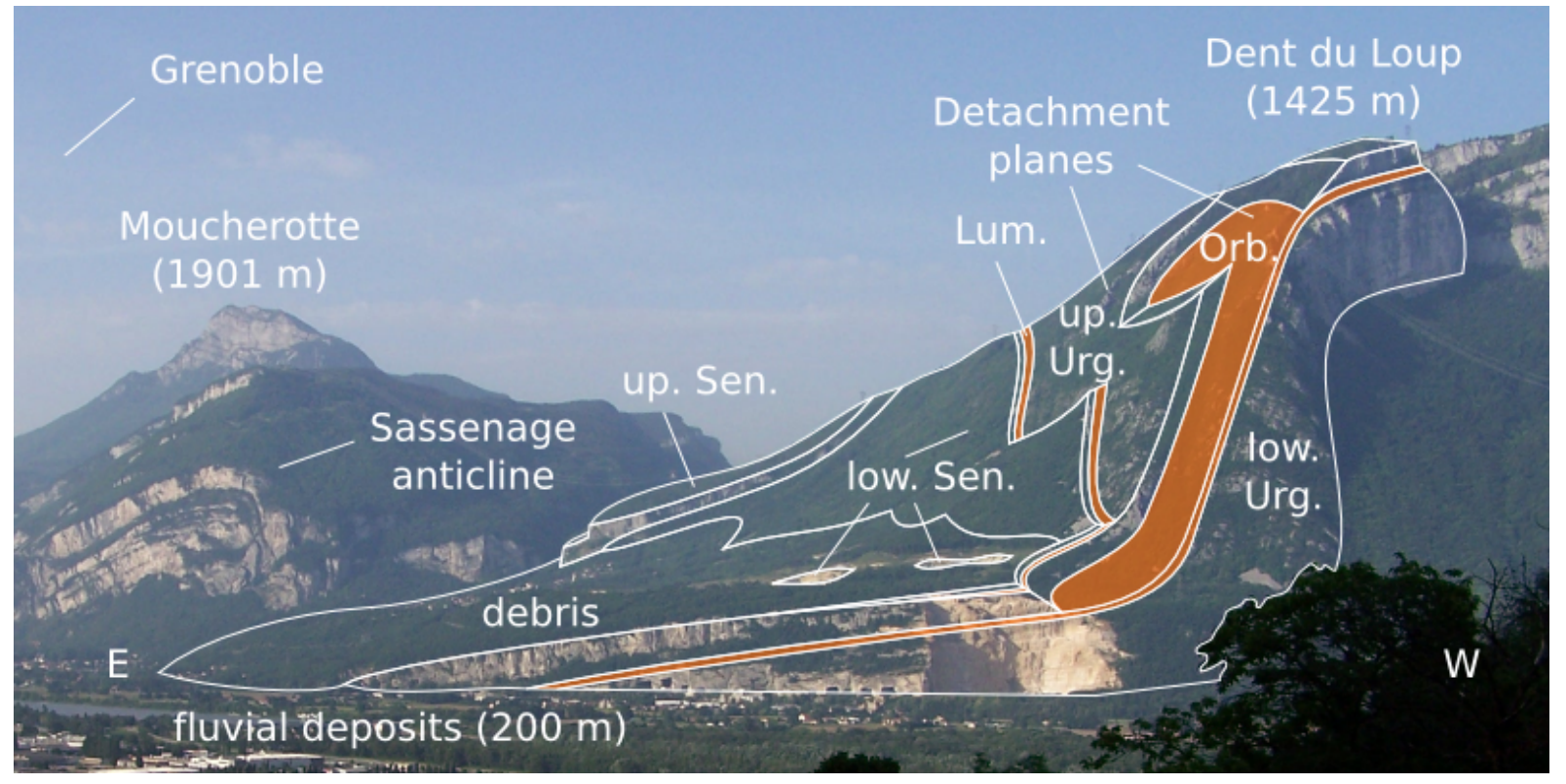

Figure 1: Interpreted photography of the Sassenage rockslide showing the different geological units. The view is taken toward South from Mont-Saint-Martin on Chartreuse slopes. Lumachelle and orbitolines layers played as weak planes. Urg.: Urgonian massive limestone; Orb.: orbitolines layer; Lum.: Aptian lumachelle; Sen.: Senonian. After the local geological map (Arnaud et al., 1978).

of highly fractured materials and exhibit down-slope velocities from 1 to $100 \mathrm{~cm} / \mathrm{yr}$ (le Roux et al., 2009). In the case of a major landslide occurrence, the filling of the Romanche valley, generating of a lake dam has to be consider. The catastrophic breaking of the dam would led to the generation of a destructive wave which would travel directly to Southern Grenoble industrial zones.

Le Roux et al. (2009) applied the cosmic ray exposure method on the head scarp of the slide to reconstruct the history of land motion. They concluded to glacier retreat from the plateau at $16.6 \pm 0.6^{10} \mathrm{Be} \mathrm{kyr}$ and initiation of the slope failure at $6.4 \pm 1.4{ }^{10} \mathrm{Be} \mathrm{kyr}$, which implies a lag time of several kyr between deglaciation and landslide initiation. This in turn suggests that post-glacial debutressing was not the only process involved in the Séchilienne slope stability.

\section{Model setup}

\subsection{Global presentation}

The evolution of deep permafrost is controlled by heat conduction and phase change, two slow processes occurring at time scales from the tenth to the thousand of years. The ground surface and first meters of soil are strongly affected by seasonal variations of air temperature, frozen / thawed state of the ground, snow cover, etc. An additional model is then needed to relate year-defined quantities such as mean temperature, temperature amplitude or seasonal indices between the lower atmosphere and the upper ground.

Following Riseborough et al. (2008), one can divide a vertical temperature profile in several distinct layers (fig. 3). Each one is governed by different processes and is associated with a different temperature (table 1). The mean annual air temperature (MAAT) 


\begin{tabular}{ll}
\hline MAAT & Mean Annual Air Temperature \\
SAAT & Seasonal half-Amplitude of Air Temperature \\
MTWA & Mean Temperature of Warmest Month \\
MTCO & Mean Temperature of Coldest Month \\
MAGST & Mean Annual Ground Surface Temperature \\
SAGST & Seasonal half-Amplitude of Ground Surface Temperature \\
TTOP & Temperature at the Top Of Permafrost \\
\hline
\end{tabular}

Table 1: List of abbreviations.

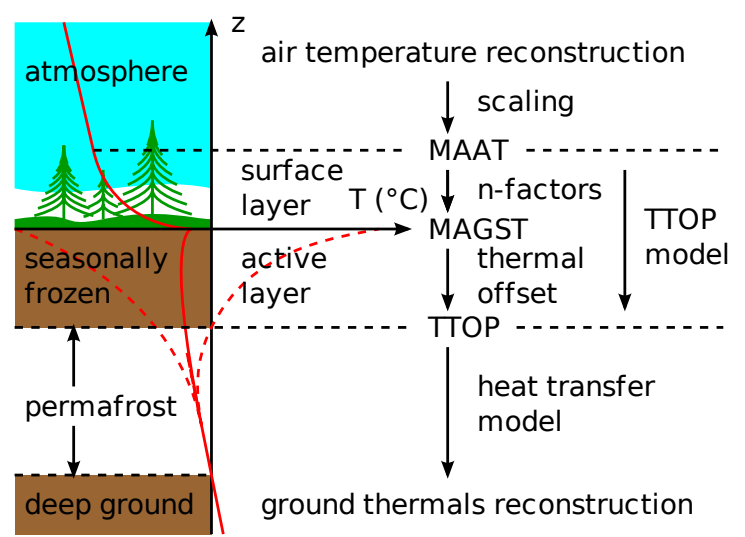

Figure 3: Schematic drawing of a vertical temperature profile (in red) and its sections according to the TTOP model. The plain line show the mean annual profile and the dashed line are the seasonal envelope. After Riseborough et al. (2008).

is the representative temperature of the lower atmosphere, which is obtained through paleo-temperature records. The surface layer seperates the mean annual ground surface temperature (MAGST) from the MAAT. The difference beween MAGST and MAAT is called surface offset and contains the isolating and albedo effects of vegetation and eventual snow cover.

Permafrost is defined as perennially frozen ground (Lliboutry, 1965). Because of a difference in thermal conductivity between frozen and thawed ground, an other difference known as thermal offset exists between the MAGST and the temperature at the top of permafrost (TTOP). In and below permafrost, the

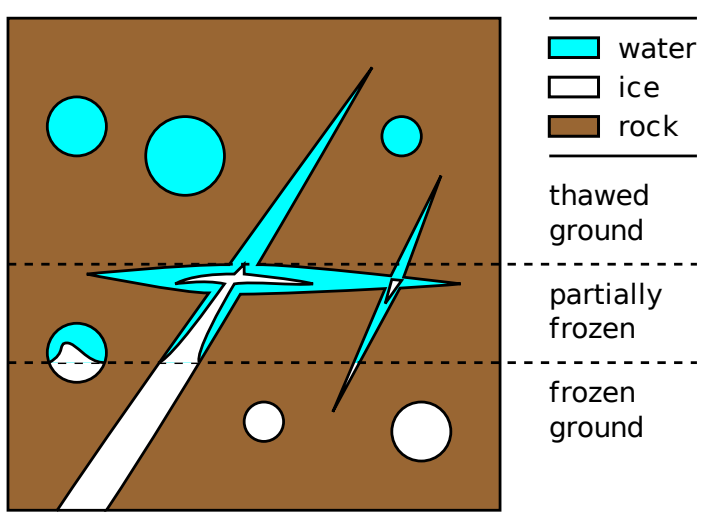

Figure 4: Schematic representation of the porous media.

ground thermal regime is governed by heat diffusion and phase change.

The thermal offset can be analytically calculated from frozen and thawed thermal conductivity of the ground. The surface offset is usually obtained by two empirical factors of correlation. The TTOP model combines the calculation of thermal and surface offset.

In the following report, the entire model will be described from the bottom to the top by increasing complexity. 


\subsection{Deep temperature evolution}

\subsubsection{Temperature diffusion}

Let consider an elementary volume $\delta V$ of mass $\delta m$ of a porous media of macroscopic density $\rho$, which contains a mass $\delta m_{T}$ of liquid water and $\delta m_{F}$ of ice (fig. 4). $w$ will denote the moisture content and $f$ the frozen content of water in the media.

$$
\begin{gathered}
w=\frac{\delta m_{T}+\delta m_{F}}{\delta m} \quad ; \quad f=\frac{\delta m_{F}}{\delta m_{T}+\delta m_{F}} \\
\delta m_{F}=w f \rho \cdot \delta V
\end{gathered}
$$

An energy balance for this volume gives:

$$
c \frac{\partial T}{\partial t} \cdot \delta m=c \dot{T} \cdot \delta m=-\operatorname{div} \vec{q} \cdot \delta V+L \cdot \delta \dot{m}_{F}
$$

The notations are defined in table 2. By neglecting the water movements, (constant $w$ and $\delta V$ ), the heat transfer equation becomes:

$$
\rho c \dot{T}=-\operatorname{div} \vec{q}+\rho L w \dot{f}
$$

The diffusive heat flux $\vec{q}$ is constrained by the Fourier law:

$$
\vec{q}=-k \cdot \operatorname{grad} T
$$

\subsubsection{Density and porosity}

One has to distinguish between the total rock density $\rho$ and the dry bulk density $\rho_{d}$. By supposing the porous media to be water-saturated, these two quantities can be related to each other using porosity $\phi$.

$$
\rho=\rho_{d}(1-\phi)+\rho_{w} \phi
$$

Where $\rho_{w}=1000 \mathrm{~kg} \cdot \mathrm{m}^{-3}$ is the density of water. Please note that porosity is define here as a volume ratio, which differ from the moisture content $w$.

$$
w \rho=\phi \rho_{w}
$$

The current model will use dry bulk density and porosity as input parameters, which are better constrained and more intuitive quantities than total density and moisture content. However, $\rho$ and $w$ will be

\begin{tabular}{cl}
\hline$\rho$ & Total density of rock \\
$\rho_{d}$ & Dry bulk density of rock \\
$c$ & Specific heat capacity of rock at \\
& constant pressure \\
$c_{e f f}$ & Effective specific heat capacity \\
$k$ & Thermal conductivity of rock \\
$T$ & Temperature \\
$\vec{q}$ & Conductive heat flux density \\
$q_{0}$ & Local geothermal flux density \\
$\phi$ & Porosity of rock \\
$w$ & Moisture content \\
$f$ & Frozen content of water \\
$\theta$ & Freezing interval \\
$L$ & Latent heat of fusion of water \\
$H$ & Heavyside function \\
\hline$k_{F}$ & Thermal conductivity of frozen ground \\
$k_{T}$ & Thermal conductivity of thawed ground \\
$k^{*}$ & Thermal conductivity at the top of \\
& permafrost \\
$r$ & Ground thermal conductivity ratio \\
$r^{*}$ & $k^{*} / k_{F}$ ratio \\
$n_{F}$ & Freezing n-factor \\
$n_{T}$ & Thawing n-factor \\
\hline$M$ & Mean annual air temperature \\
$A$ & Half-amplitude of air temperature \\
$I_{F A}$ & Seasonal index of air freezing \\
$I_{T A}$ & Seasonal index of air thawing \\
$I_{F S}$ & Seasonal index of surface freezing \\
$I_{T S}$ & Seasonal index of surface thawing \\
$P$ & Period of temperature fluctuations \\
\hline &
\end{tabular}

Table 2: Notations.

used instead of $\rho_{d}$ and $\phi$ in the following equations to lighten the script. Using the two previous equations, one can develop the expression of moisture content:

$$
w=\frac{1}{1+\left(\frac{1}{\phi}-1\right) \frac{\rho_{d}}{\rho_{w}}}
$$

\subsubsection{Phase changes}

The question of the propagation of a melting (or freezing) front within one dimension $x$ can be analytically resolved. It is however not easily numerically implemented, especially if the model involves several 
dimensions or multiples fronts. This is why a continuous formulation will be used instead.
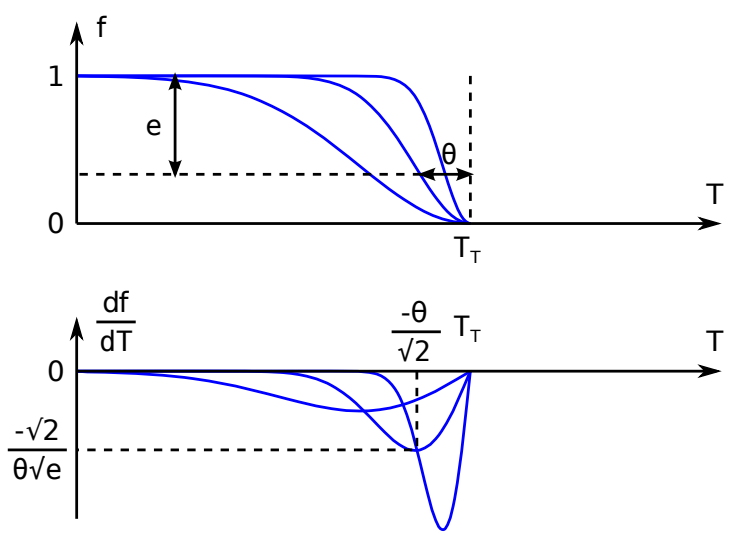

Figure 5: Frozen content as a function of temperature for the Gaussian model.

The model proposed by Mottaghy and Rath (2006) and applied by Noetzli (2008); Noetzli and Gruber (2008) consider the presence of unfrozen water within the porous media at slightly negative temperatures. The frozen content $f$ below the melting point $T_{T}$ is described by a Gaussian function (fig. 5).

$$
\begin{aligned}
& f=H\left(T_{T}-T\right) \cdot\left[1-e^{-\left(\frac{T_{T}-T}{\theta}\right)^{2}}\right] \\
& \dot{f}=\dot{T} \cdot H\left(T_{T}-T\right) \cdot \frac{2 T}{\theta^{2}} e^{-\left(\frac{T_{T}-T}{\theta}\right)^{2}}
\end{aligned}
$$

Where $\theta$ is a freezing interval usually found between one and a few Celsius degrees. An effective specific heat capacity can then be introduced:

$$
c_{\text {eff }}=c+L w \cdot H\left(T_{T}-T\right) \cdot \frac{2 T}{\theta^{2}} e^{-\left(\frac{T_{T}-T}{\theta}\right)^{2}}
$$

And equation (1) is reduced to:

$$
\rho c_{e f f} \dot{T}=-\operatorname{div} \vec{q}
$$

A fully physical model of deep temperature evolution in the presence of permafrost is established. This model needs however an upper boundary condition that takes account of seasonal variations and surface effects.

\subsection{Surface effects}

\subsubsection{The thermal offset}

In a simple one-dimension heat diffusion problem, the effect of any time-periodic anomaly at ground surface would only affect a thermal boundary layer and decrease exponentially with depth. This is a basic result from diffusion equation solving under periodic conditions. However, in the case of a seasonally freezing and thawing ground, one have to consider the difference of thermal conductivity between the two phases. Frozen ground is a better thermal conductor than thawed ground, and this causes the temperature at the base of the boundary layer, which is here equivalent with the temperature at the top of permafrost (TTOP) to be lower than the mean temperature at ground surface (MAGST). This effect is known as thermal offset. It has been numerically illustrated by Delisle (1998), and increase with seasonal amplitude of ground surface temperature (SAGST) and ground conductivity contrast.

The TTOP can be related to the ground surface temperature using seasonal freezing $I_{F S}$ and thawing $I_{T S}$ degree day indexes (Smith and Riseborough, 1996).

$$
\begin{gathered}
\text { TTOP }=\frac{k_{T} I_{T S}-k_{F} I_{F S}}{k^{*} P} \\
k^{*}=\left\{\begin{array}{lll}
k_{F} & \text { if } & k_{T} I_{T S}-k_{F} I_{F S}<0 \\
k_{T} & \text { if } & k_{T} I_{T S}-k_{F} I_{F S}>0
\end{array}\right.
\end{gathered}
$$

Where $k_{F}$ and $k_{T}$ are the thermal conductivities of frozen and thawed ground, and $P$ the period (365.25 days) of temperature fluctuations, as defined in table 2. The thermal offset can then be calculated as a function of ground surface conditions. Modelling the surface layer effects is but a more complex problem.

\subsubsection{The $\mathrm{n}$-factors}

The effects of vegetation, snow cover and soil organic horizon are usually modelled by the n-factor theory (Lunardini, 1978; Jorgensen and Kreig, 1988; Smith and Riseborough, 1996) of correlation between surface and air seasonal indexes.

$$
I_{T S}=n_{T} I_{T A} \quad \text { and } \quad I_{F S}=n_{F} I_{F A}
$$


Using equation (5) one can combine the effects of active and surface layers to obtain the TTOP model.

$$
\mathrm{TTOP}=\frac{k_{T} n_{T} I_{T A}-k_{F} n_{F} I_{F A}}{k^{*} P}
$$

Seasonal indexes could easily be deduced from daily measurements of a meteorological station. $n_{T}$ and $n_{F}$ are usually found between 0 and 2 . In order to apply to the TTOP model to past temperature reconstructions, one has but to develop it in terms of mean temperature and temperature amplitude.

\subsubsection{The Kudryatsev equation}

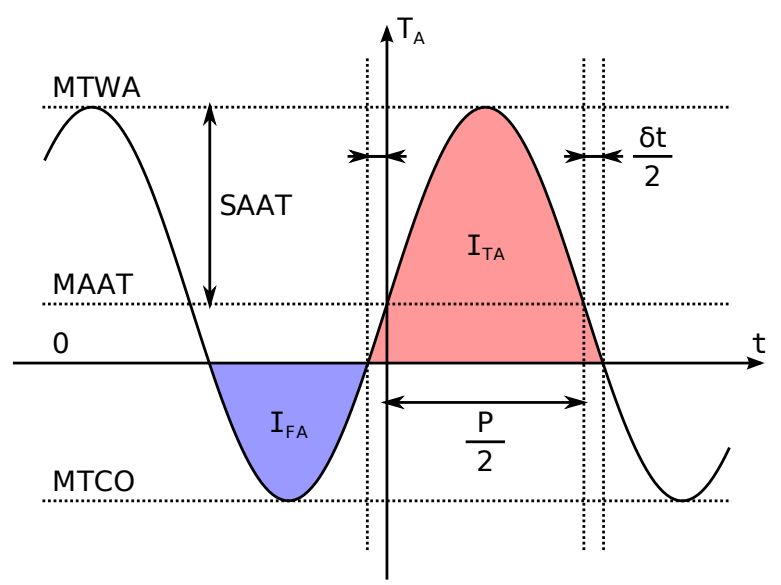

Figure 6: Sinusoidal model of seasonal air temperature evolution.

Paleo-temperature reconstructions are generally expressed in terms of mean temperature of the warmest month (MTWA) and mean temperature of the coldest month (MTCO). By assuming a sinusoidal evolution of the air temperature between these two extremes (fig. 6), this formulation is equivalent with mean (MAAT) and amplitude (SAAT) formulation.

$$
\begin{gathered}
T_{A}=M+A \cdot \sin \frac{2 \pi t}{P} \\
M=\mathrm{MAAT}=\frac{\mathrm{MTWA}+\mathrm{MTCO}}{2} \\
A=\mathrm{SAAT}=\frac{\mathrm{MTWA}-\mathrm{MTCO}}{2}
\end{gathered}
$$

To obtain the expression of degree days of freezing and thawing, let consider a time interval $\delta t$ defined by $T_{A}\left(-\frac{\delta t}{2}\right)=0$, which is equivalent with $M=A \sin \frac{2 \pi \delta t}{2}$, or $\delta t=\frac{P}{\pi} \arcsin \frac{M}{A}$.

$$
\begin{aligned}
I_{T A}=\int_{-\frac{\delta t}{2}}^{\frac{P+\delta t}{2}} T_{A} \cdot d t=M\left(\frac{P}{2}+\delta t\right)+\frac{A P}{\pi} \cos \frac{\pi \delta t}{P} \\
-I_{F A}=\int_{\frac{\delta t-P}{2}}^{\frac{\delta t}{2}} T_{A} \cdot d t=M\left(\frac{P}{2}-\delta t\right)-\frac{A P}{\pi} \cos \frac{\pi \delta t}{P} \\
I_{T A}-I_{F A}=M \cdot P \\
I_{T A}+I_{F A}=2 M \delta t+\frac{2 A P}{\pi} \cos \frac{\pi \delta t}{P} \\
=\frac{2 P}{\pi}\left(M \arcsin \frac{M}{A}+\sqrt{A^{2}-M^{2}}\right)
\end{aligned}
$$

One can then deduce the expression for TTOP from equation (6).

$$
\begin{aligned}
\text { TTOP } & =\frac{k_{T} n_{T} I_{T A}-k_{F} n_{F} I_{F A}}{k^{*} P} \\
= & \frac{k_{T} n_{T}-k_{F} n_{F}}{k^{*}} \cdot \frac{I_{T A}+I_{F A}}{2 P} \\
& +\frac{k_{T} n_{T}+k_{F} n_{F}}{k^{*}} \cdot \frac{I_{T A}-I_{F A}}{2 P} \\
= & \frac{r n_{T}-n_{F}}{r^{*} \pi}\left(M \arcsin \frac{M}{A}+\sqrt{A^{2}-M^{2}}\right) \\
& +\frac{r n_{T}+n_{F}}{r^{*}} \cdot \frac{M}{2}
\end{aligned}
$$

Where $r=\frac{k_{T}}{k_{F}}$ and $r^{*}=\frac{k^{*}}{k_{F}}$. This is the Kudryatsev equation. Please note that the equation was corrected from Riseborough et al. (2008) and Duan and Naterer (2009) where an homogeneity mistake appears in the $M^{2}$ term. Note also that this equation keeps available only while $A^{2} \geq M^{2}$. To have a complete model, one has to consider the two special cases where ground surface keeps perennially frozen (seldom) or perennially thawed (common).

$$
\begin{array}{ccl}
\text { If } M \leq A & \text { then } & I_{F A}=-M P \text { and } I_{T A}=0 \\
& \Rightarrow & \text { TTOP }=n_{F} M \\
\text { If } M \geq A & \text { then } & I_{F A}=0 \text { and } I_{T A}=M P \\
\Rightarrow & \text { TTOP }=n_{T} M
\end{array}
$$

The TTOP can now be calculated as a function of past atmospheric conditions. 


\subsubsection{Testing the TTOP model}

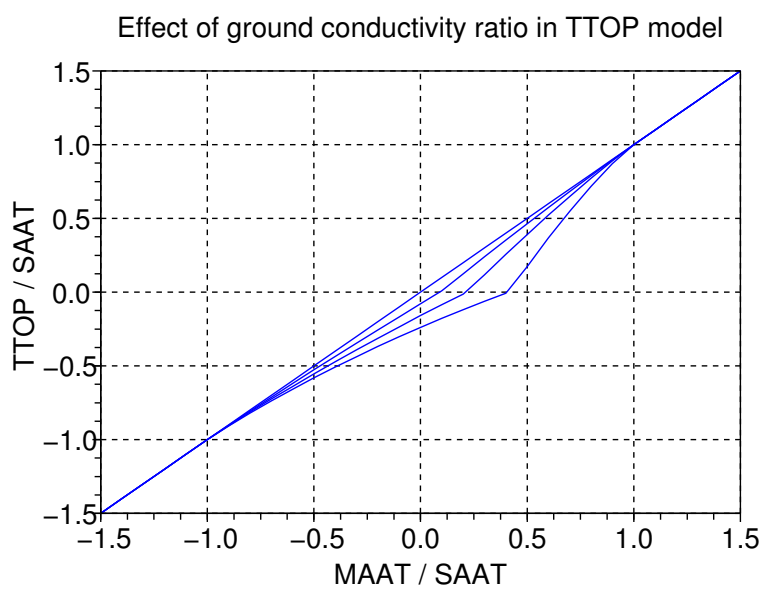

Figure 7: TTOP as a function of MAAT for different values of conductivity ratio $r=\{1 ; 0.75 ; 0.5 ; 0.25\}$ and $n_{F}=n_{T}=1$.

As seen in equation 7, the TTOP model involves three parameters: ground conductivity ratio $r$ and freezing $n_{F}$ and thawing $n_{T}$ factors. Figure 7 shows the influence of conductivity ratio, keeping $n_{F}=$ $n_{T}=1$. It basically demonstrate the effect of thermal offset. One can notice that for $r=1$ - what would be the case of a dry, massive exposed bedrock - TTOP equals MAAT. For lower values, a negative offset reaching up half SAAT can be found.

Figures 8 and 9 shows the respective influences of the two $\mathrm{n}$-factors, keeping $r=0.5$. Each $\mathrm{n}$-factor acts on its part of the profile. One can observe that for large absolute values of MAAT compared with SAAT, the surface offset can be much higher than the thermal offset.

\subsection{Air temperature reconstruction}

Reconstructing quantitative Holocene climates in south-eastern France is probably one of the most complex requirements of the current model. It will be fulfilled by using pollen-based reconstructions, which are probably the best fitting method for the given place and time scale, and besides got the big ad-

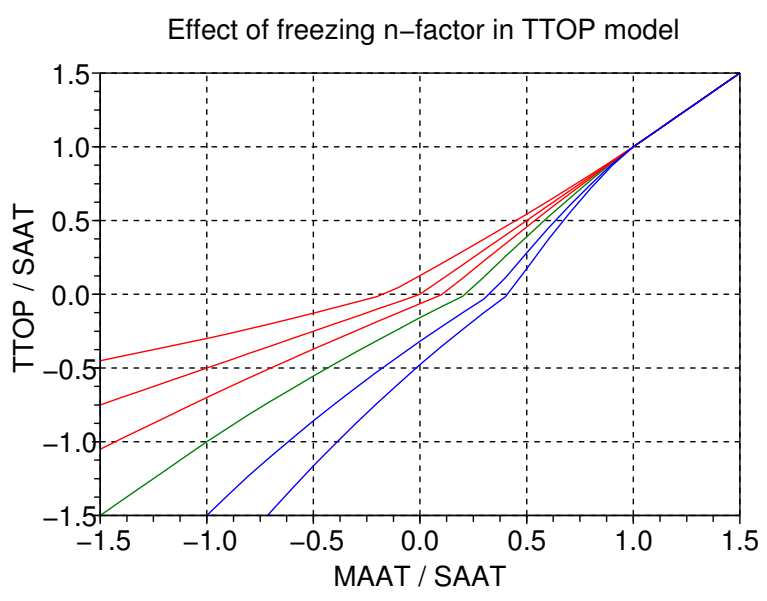

Figure 8: TTOP as a function of MAAT for different values of freezing n-factor $n_{F}=\{0.3 ; 0.5 ; 0.7\}$ (red), $n_{F}=1$ (green) and $n_{F}=\{1.5 ; 2\}$ (blue). $r=0.5$ and $n_{T}=1$.

vantage of providing both MTCO and MTWA (or MAAT) records, which allows to calculate the TTOP.

The principle of the method is to assign a past climate to a fossil pollen using modern analogue matching and correlation of modern pollen with modern climates. This mattered when reconstructing cold climates of the last glacial because of a lack of modern analogues. Peyron et al. (1998) improved a newly developed method which gather pollen taxa into plant functional types and thus enhance correlations. This allowed to reconstruct 18 kyr B.P climate for 15 European sites, including Les Echets, located near Lyon, some $100 \mathrm{~km}$ North-West of Grenoble out of the alpine glaciations maximum extent area, where Peyron et al. (1998) concluded to a $-12(+3 ;-$ 1 incertitude $)^{\circ} \mathrm{C}$ MAAT anomaly and $-27(+6 ;-18)^{\circ} \mathrm{C}$ MTCO anomaly.

Using an enhance plant functional types method, Davis et al. (2003) published the first pollen-based Holocene temperature time series by collecting data from 510 sites located in 6 regions parted Europe. The presented curve for MTCO and MTWA anomalies of the Central Western Europe region during the last $12 \mathrm{kyr}$ will be used (as retrieved from the electronic paper) in the current model. It however does 


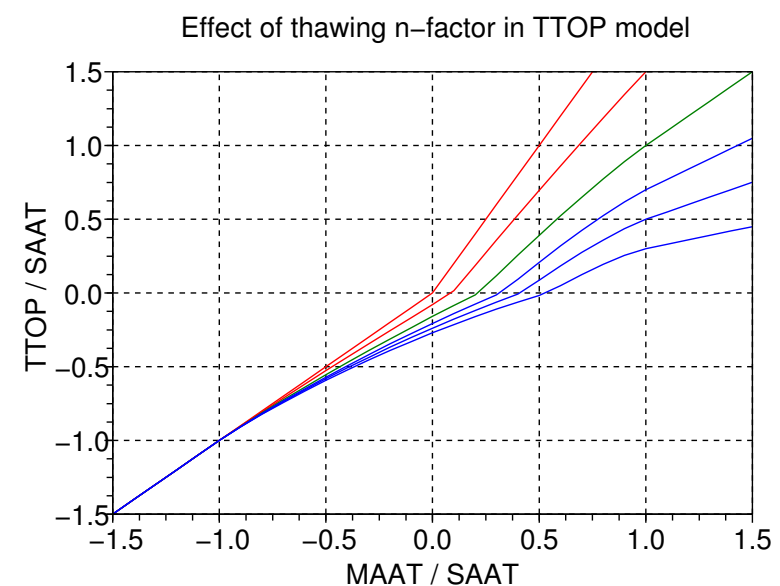

Figure 9: TTOP as a function of MAAT for different values of thawing $\mathrm{n}$-factor $n_{T}=\{0.3 ; 0.5 ; 0.7\}$ (blue), $n_{T}=1$ (green) and $n_{T}=\{1.5 ; 2\}$ (red). $r=0.5$ and $n_{F}=1$.

not exhibit Younger Dryas and late glacial temperatures. This is why the Peyron et al. (1998) data will be used as initial condition and extrapolated between 18 and $12 \mathrm{kyr}$ B.P, which is equivalent with starting the computations at the end of the Younger Dryas at 12 kyr B.P, and ignore Allerød interstadial transient effects.

Finally, these temperatures anomaly were converted to absolute temperature using 1968-1990 averages from the local Grenoble Saint-Geoirs meteorological station (Infoclimat, 2009). Figure 10 shows the resulting temperature scenario in terms of MAAT, MTCO and MTWA. One would observe that glacial summers are paradoxically hotter than current ones. This results from the Peyron et al. (1998) very low winter temperature and the previous sinusoidal assumption. These very low MTCO are however a disputed result in total disagreement with stationary runs of global circulation models, and research is still carried out to improve both reconstruction and modelling methods (Ramstein et al., 2007). In between, a full model of permafrost evolution from temperature reconstruction has now been established.

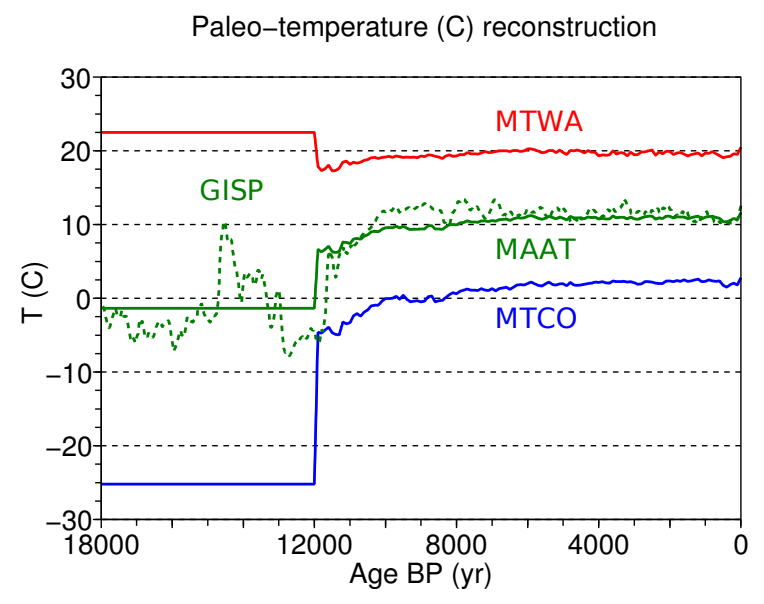

Figure 10: Paleo-temperature reconstruction used in the model. Pollen-based winter (MTCO), summer (MTWA) and mean (MAAT) temperatures after Peyron et al. (1998); Davis et al. (2003) and Infoclimat (2009). Shifted GISP ice core record from Alley (2000, 2004) data as dashed line for comparison.

\section{1D sensibility tests}

\subsection{Numerical implementation}

The model described above was numerically implemented in a one dimension (1D) finite difference program under the Scilab matrix-oriented free mathematical software. After preliminary calculation of the TTOP, the evolution of deep temperature is resolved by a first-order implicit scheme using a tri-diagonal matrix inversion algorhythm, which enable very fast computations and lightened script. (See program code in appendix).

All the following presented results concern the temperature evolution of a $500 \mathrm{~m}$ deep vertical profile through the past $12 \mathrm{kyr}$. To model an altitude effect, a $-6^{\circ} \mathrm{C}$ shift was applied to the temperature conditions described above. Since Grenoble Saint-Geoirs meteorological station is $384 \mathrm{~m}$ above sea level, we can consider the following simulations to concern a roughly $1500 \mathrm{~m}$ high plateau. The initial state is set as the equilibrium thermal profile at $12 \mathrm{kyr}$ (or $18 \mathrm{kyr})$ B.P, and therefore depends on input param- 


\begin{tabular}{clccccc} 
& Model parameter & Typical range & Default & Unit & Thaw ages (yr) & Range \\
\hline$\rho_{d}$ & Dry bulk density & $2500-3100$ & 2650 & $\mathrm{~kg} \cdot \mathrm{m}^{-3}$ & $10240-10170$ & 70 \\
$c$ & Specific heat capacity & $500-1000$ & 800 & $\mathrm{~J} \cdot \mathrm{kg}^{-1} \cdot{ }^{\circ} \mathrm{C}^{-1}$ & $10350-10140$ & 210 \\
$k$ & Thermal conductivity & $0.5-3.5$ & 2.5 & $\mathrm{~W} \cdot \mathrm{m}^{-1} \cdot{ }^{\circ} \mathrm{C}^{-1}$ & $11220-10030$ & 1190 \\
$q_{0}$ & Geothermal flux & $30-50$ & 40 & $\mathrm{~mW} \cdot \mathrm{m}^{-2}$ & $10630-9460$ & 1170 \\
$\theta$ & Freezing interval & $0.03-3$ & 0.3 & ${ }^{\circ} \mathrm{C}$ & $11050-9970$ & 1080 \\
$\phi$ & Porosity & $0.1-30$ & 3 & $\%$ & $11160-4620$ & 6540 \\
$r$ & Ground conductivity ratio & $0.25-1$ & 0.5 & - & $11290-9170$ & 2120 \\
$n_{F}$ & Freezing n-factor & $0.3-2$ & 0.5 & - & $11550-4060$ & 7490 \\
$n_{T}$ & Thawing n-factor & $0.3-1$ & 0.7 & - & $11840-6350$ & 5490 \\
$L$ & Latent heat of fusion of water & - & 330000 & ${\mathrm{~J} . \mathrm{kg}^{-1}}^{-1}$ & - & - \\
\hline
\end{tabular}

Table 3: Chosen variation ranges, defaults parameters used in computations and resulting variability in modelled age of last permafrost thawing.

eters. After testing different grids, the space resolution was set to $10 \mathrm{~m}$ and the time step to $10 \mathrm{yr}$, which seemed to reduce numerical errors to less than $1 \%$, and allows very fast resolution.

\subsection{Choice of parameters}

Application of the previous model involves numerous parameters associated with various incertitudes. Table 3 gather typical parameter ranges in regard to Sassenage and Séchilienne failure slopes and potentially other similar alpine sites. A default set of parameters was also chosen as most probable values.

Thermal parameters $\rho_{d}, c$ and $k$ ranges are representative for an all rocks variability (Berest et al., 1988; Cailleux, 1974; Carmichael, 1984; Fowler, 2005; Stacey and Davis, 2008). Default values agree with massive limestone as well as mean rock properties. The continental mean of geothermal flux is of $65 \mathrm{~mW} \cdot \mathrm{m}^{-2}$ (Fowler, 2005; Stacey and Davis, 2008). However, the 1D simulations will use an interval of lower values in order to take account of the diverging effect of a plateau and scarp morphology.

Freezing interval range include all values cited by Mottaghy and Rath (2006); Noetzli (2008); Noetzli and Gruber (2008); Wegmann et al. (1998). The wide range of porosity values stands for very variable conditions going from a highly coherent micaschist to a weak and fractured limestone. It is hardly quantified mostly because of the unknown density of an eventual fracture network.

Following Smith and Riseborough (1996), the ground conductivity ratio can vary between 0.25 and 1 with a mean 0.5 value. Freezing and thawing nfactors range take accounts of all measured and proposed values from Jorgensen and Kreig (1988); Lunardini (1978). Default values are the same as in Smith and Riseborough (1996).

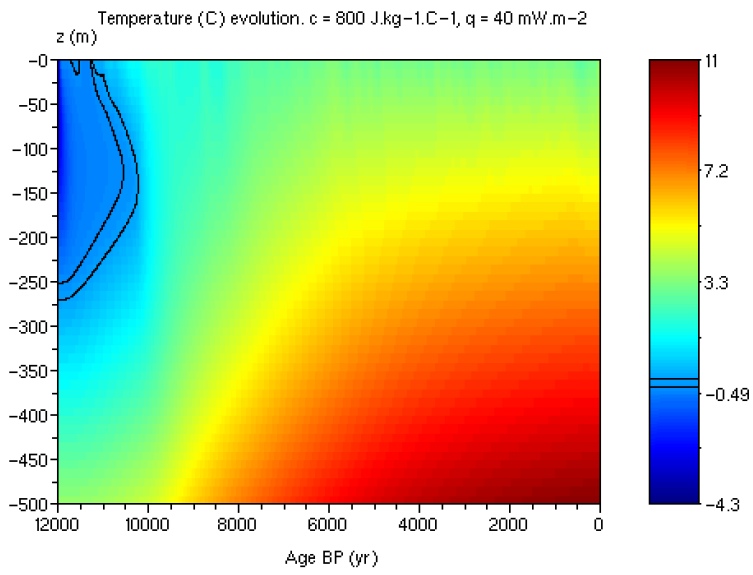

Figure 11: Temperature $T$ time evolution of a $500 \mathrm{~m}$ deep vertical profile using $1 \mathrm{D}$ model default parameters defined in table 3 . The two black lines denotes $-\theta$ and $0^{\circ} \mathrm{C}$ isotherms. 

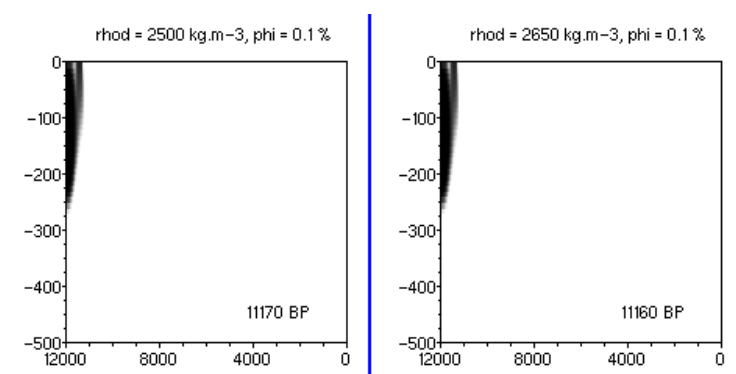

rhod $=2500 \mathrm{~kg} \cdot \mathrm{m}-3, \mathrm{phi}=0.3 \%$
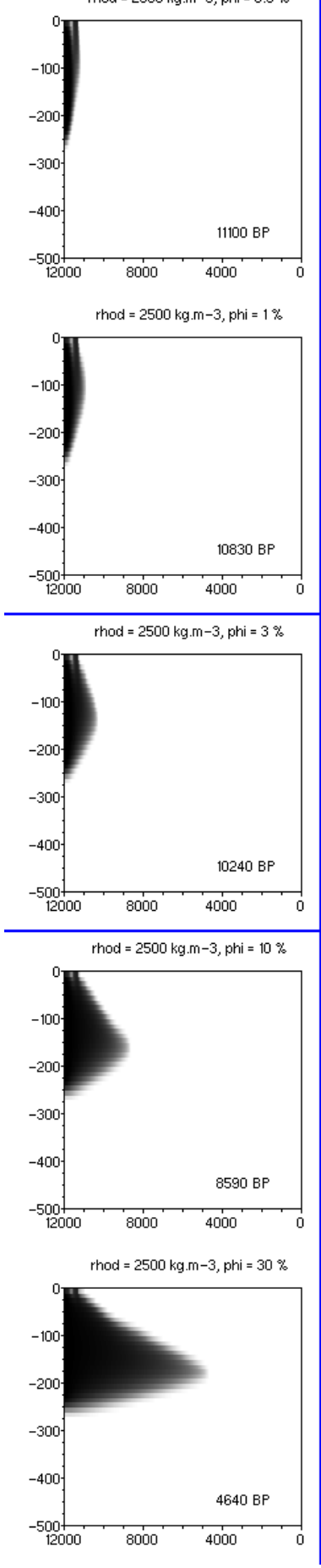

rhod $=2650 \mathrm{~kg} \cdot \mathrm{m}-3$, phi $=0.3 \%$
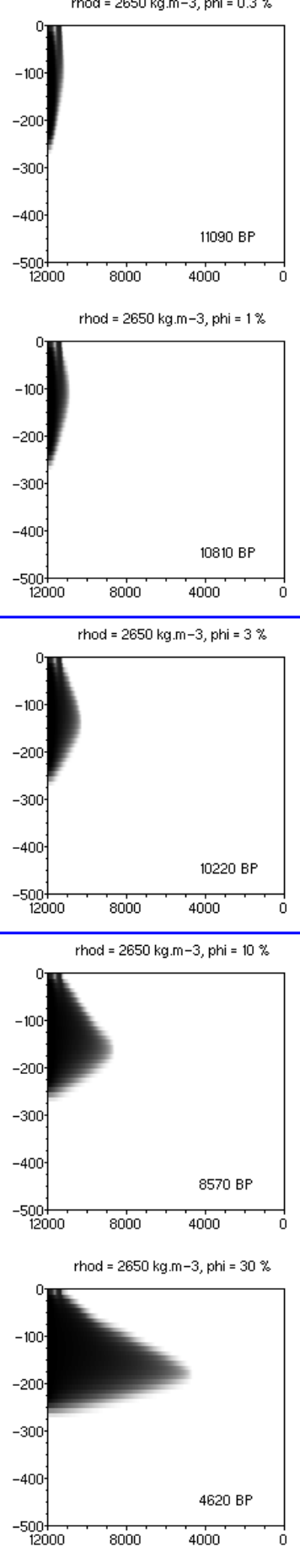

rhod $=2800 \mathrm{~kg} \cdot \mathrm{m}-3, \mathrm{phi}=0.1 \%$
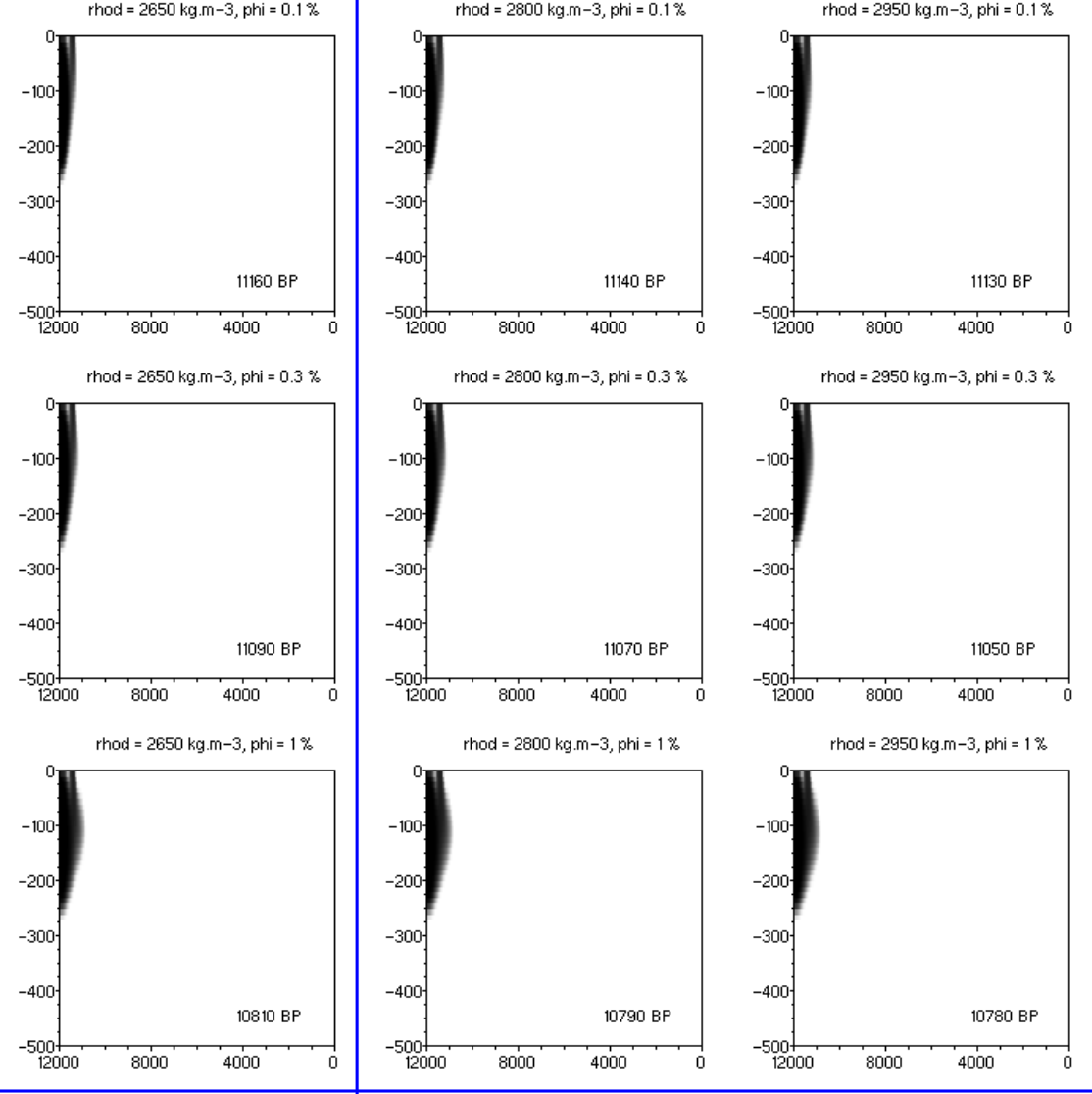

rhod $=2950 \mathrm{~kg} \cdot \mathrm{m}-3, \mathrm{phi}=0.3 \%$

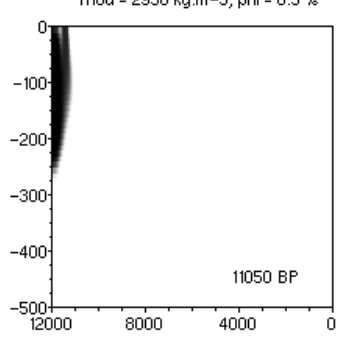

rhod $=2950 \mathrm{~kg} \cdot \mathrm{m}-3, \mathrm{phi}=3 \%$
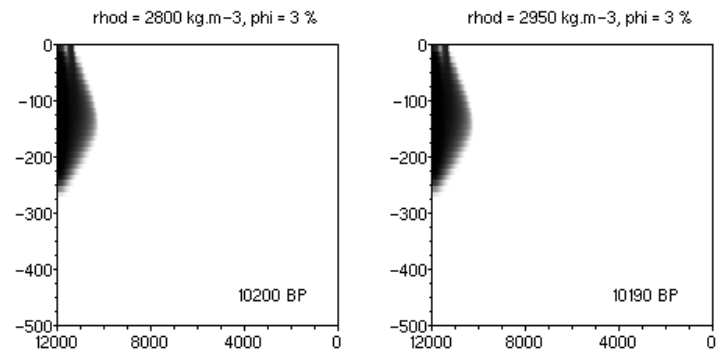

rhod $=3100 \mathrm{~kg} \cdot \mathrm{m}-3, \mathrm{phi}=3 \%$

rhod $=2800 \mathrm{~kg} . \mathrm{m}-3$, phi $=10 \%$

rhod $=2950 \mathrm{~kg} . \mathrm{m}-3, \mathrm{phi}=10 \%$
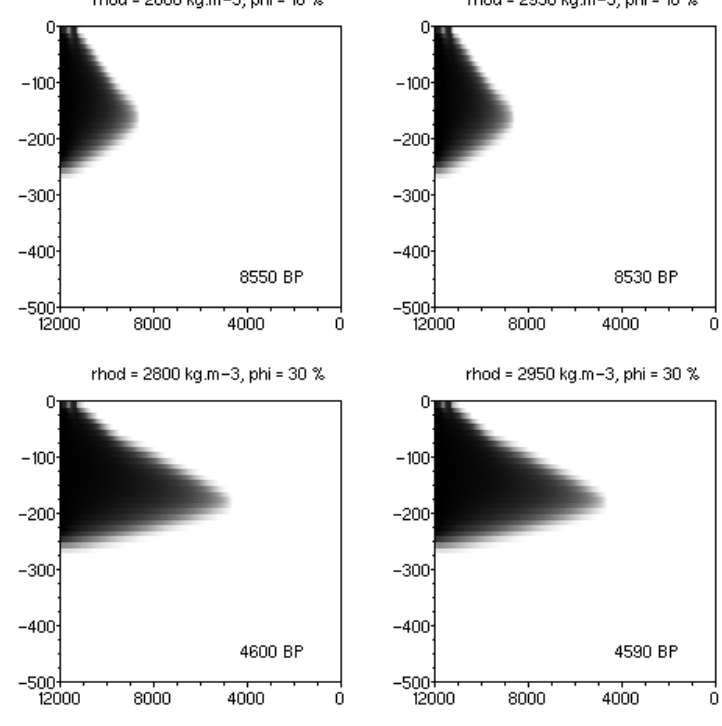

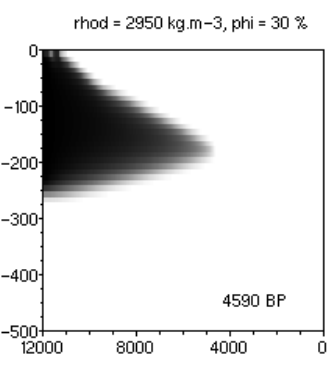

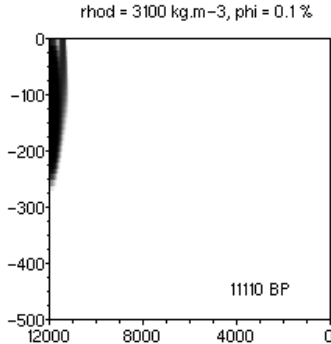

rhod $=3100 \mathrm{~kg} \cdot \mathrm{m}-3, \mathrm{phi}=0.3 \%$
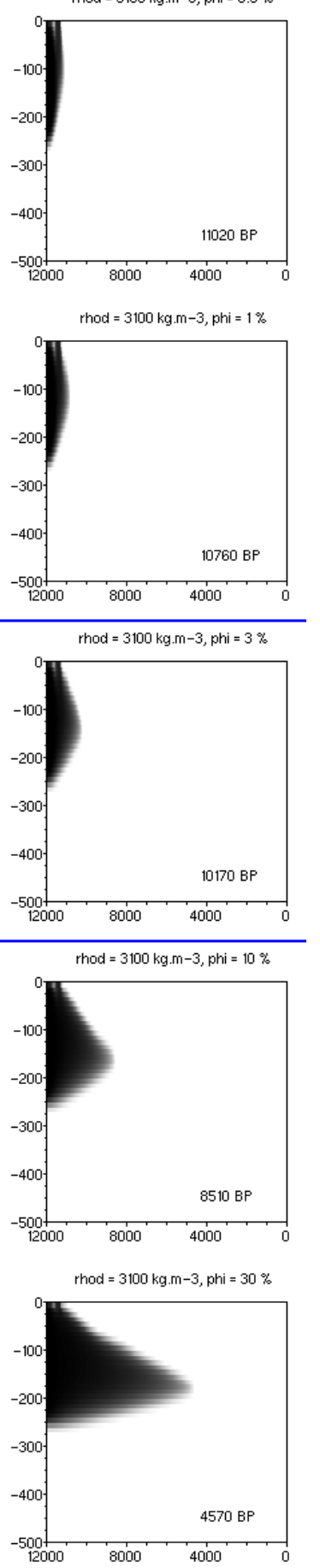

Figure 12: Sensibility test of the 1D model for varying $\rho_{d}$ and $\phi$ while keeping other parameters as the default values given in table 3. The default experiment is squared by plain lines. The graphs represent the massive frozen content $f$ of water as a shade of gray going from black ( $f=1$, fully frozen ground) to white ( $f=0$, fully thawed). The B.P age of last permafrost thawing is given in the right-bottom corner. 


\subsection{Results}

Since parameters incertitudes are sometimes wide, the 1D program was used to perform sensibility tests of the model. 463 computations were ran by varying two different parameters in the corresponding ranges while keeping the others as default values. For each single experiment, the resulting temperature $T$ evolution was output in a colored time-depth diagram of the type of figure 11. For each of the 16 selected couples of parameters, all the resulting frozen content $f$ evolutions were plotted in similar time-depth diagrams and gathered in a table plate of the type of figure 12. (See more plates in appendix). When existing, the age of last permafrost thaw was calculated.

This allowed to give a good overview of the influence of each parameter uncertainty on the model. Since all the plates can not be presented here, the variability in observed last permafrost melting ages was reported in table 3 for each parameter (keeping all others as constant).

One can immediately notice that dry bulk density $\rho_{d}$ and specific heat $c$ are the best constrained (in terms of both parameter incertitude and model variability) parameters of the model with relative influence on the order of 4 and 10\%. This demonstrates that the evolution of deep permafrost is rather controlled by phase change effects than thermal diffusion. $\rho_{d}$ and $c$ will be qualified as thermal transient parameters.

The other thermal parameters, conductivity $k$ and geothermal flux $q_{0}$, induce a variability on thaw age on the order of $50 \%$. The main reason for that is that $k$ and $q_{0}$ not only have transients effect but also affect the initial temperature profile and consequently the initial quantity of permafrost. The more ice there initially is the longer time it takes to melt. This is why $k$ and $q_{0}$ can be qualified as thermal stationary parameters.

Freezing interval $\theta$ and porosity $\phi$ are the two phase change parameters. The freezing interval does not fundamentally affect thawing dynamics. However, when reaching relatively high $\left(\theta \geq 1^{\circ} \mathrm{C}\right)$ values, it modifies initial ice quantity in permafrost, which causes the $50 \%$ variability.
Porosity is definitely the more influent deep parameter with induced variability on the order of $350 \%$. It is actually the only parameter that directly affect the thawing dynamics: the more frozen water is contained in the rock, the more energy it needs to melt.

The three surface parameters $r, n_{F}$ and $n_{T}$ are also very influent, cancelling any hope to realistically quantify the total uncertainty on the results. This demonstrates that the surface layers are the most problematic part of the current model.

\section{$52 \mathrm{D}$ modelling experiments}

\subsection{Numerical Implementation}

Despite of the large uncertainties obtained in one dimension, the model was implemented in a two dimension (2D) geometry under the Comsol Multiphysics finite element solver software. The chosen morphology consist in a $1 \mathrm{~km}$ high scarp representing the slope of a deglaciated valley. The total grid is $3 \mathrm{~km}$ wide and $5 \mathrm{~km}$ deep to limit side effects.

Contrary to the $1 \mathrm{D}$ model, the basal condition is imposed by a $65 \mathrm{~mW} . \mathrm{m}^{-2}$ geothermal flux. A symmetric condition (null horizontal heat flux) is applied on both sides of the grid. To model the effect of elevation, a constant $5^{\circ} \mathrm{C} \cdot \mathrm{km}^{-1}$ MAAT gradient is applied, with $384 \mathrm{~m}$ elevation (Grenoble Saint-Geoirs averages) at the bottom of the slope. The resulting (Scilab calculated) TTOP is set as upper boundary condition.

Computations were made on three different geometries using 30,45 and $60^{\circ}$ slope angles (fig. 13).

\subsection{Results}

In the three experiments, the initial 12 kyr B.P steady-state consist in a thick permafrost layer located under the $1000 \mathrm{~m}$ high plateau and the scarp slope. During the warming phase, when the atmospheric $0^{\circ} \mathrm{C}$ isotherm rise above the plateau, an elongated zone of permafrost is separated from the surface. Because the model dynamics are controlled by phase changes, the temperature of this permafrost core rapidly diffuse down to a homogeneous $0^{\circ} \mathrm{C}$ dis- 
tribution. The core then acts as a thermal well. It progressively melts from every directions until it completely disappears and allows heat diffusion to equilibrate the thermal profile again.

The late permafrost core is found to locate in depth at the side of the plateau. This is an effect of the imposed topography which acts on the thermal flux lines pattern. The concave point base of the scarp act as a converging point, while strong diversion of the heat discharge field is observed at the convex point of plateau extremity. This effect is emphasized by the steep 45 and $60^{\circ}$ topographies and affects the thawing dynamics (fig. 13).

The three experiments concluded to ages of last permafrost thawing of $11100\left(30^{\circ}\right), 10960\left(45^{\circ}\right)$, and 10810 yr $\left(60^{\circ}\right)$ B.P. Figure 13 represent the thermal state of the three slopes at 11000 B.P, when the last permafrost just disappeared in the first experience, and only a small permafrost core is left in the two others. It illustrates that this topography effect is relatively reduced in regard with the previously demonstrated parameter sensibility of the model.

\section{Discussion}

\subsection{Model variability}

At the current state of the study, the role of permafrost in slope instability and the possible correlation of permafrost thawing with failure initiation remains unsolved issues. The very large variability of the model prevent it from any reasonable estimation of permafrost thaw rates under the selected case studies. This variability results from both parameter incertitudes and model sensibility. If the default simulation present a $2 \mathrm{kyr}$ long thaw of permafrost, other simulations presenting nearly instantaneous thaw or present-day relict permafrost stand within the incertitudes. Concerning the Séchilienne landslide, the scenario of a 6.4 kyr B.P disappearing of permafrost correlated with slope failure initiation therefore can not be rejected, as well as it can not be validated.

However, the current study allowed to identify the main parameters causing this large variability. Concerning deep temperature evolution, porosity of the
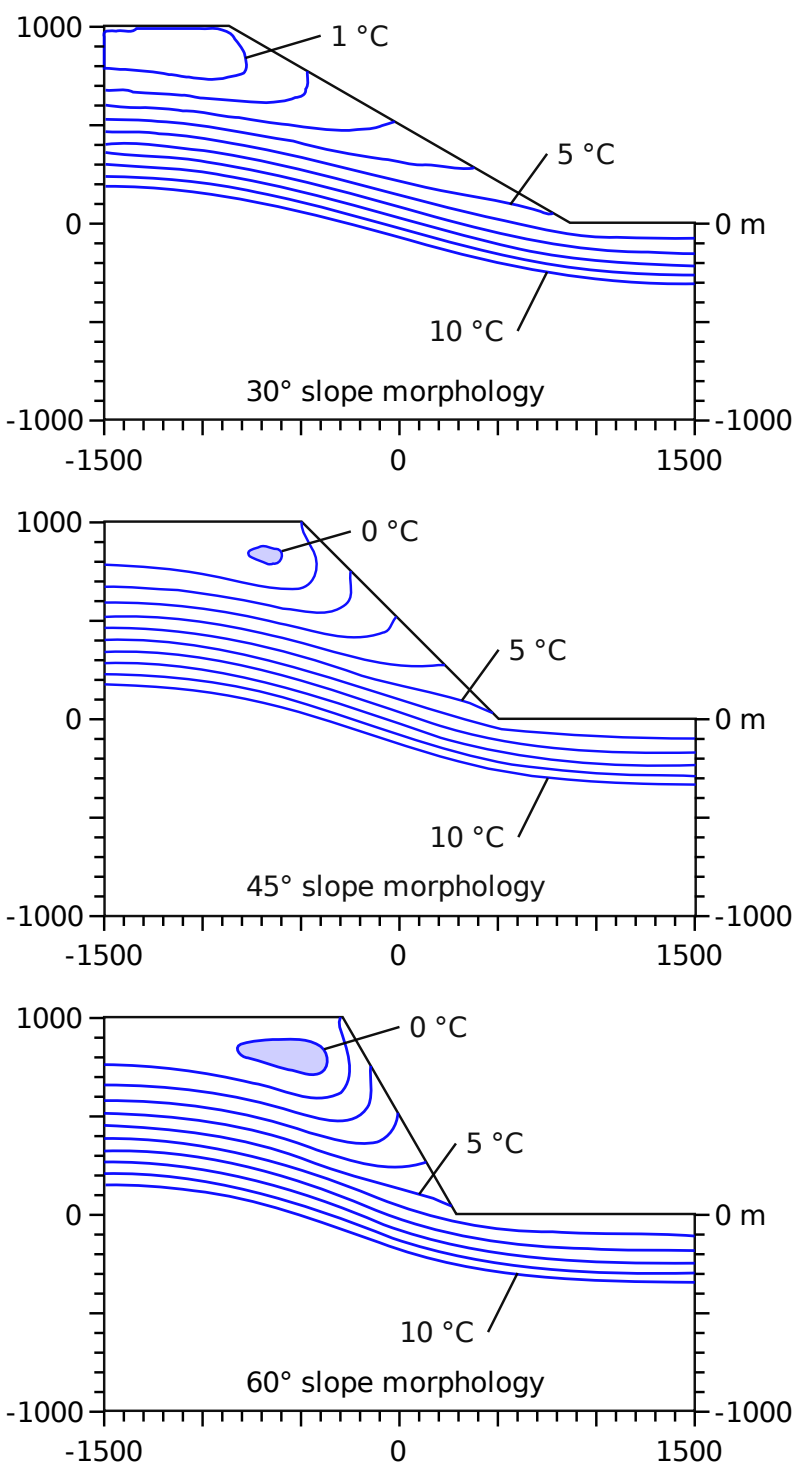

Figure 13: 2D modelling results on the three different morphologies. The blue lines are the $T \leq 10^{\circ} \mathrm{C}$ isotherms at $11 \mathrm{kyr}$ B.P. Note the heat flux diverging effect of the steep topographies. 
media is definitely the main consequent variable. Furthermore, the comprehension of heat transfer surface processes remain globally unsure. It is but possible to reduce these two uncertainties.

Concerning porosity, a better knowledge of the concerned landslides is needed. Sampling and local measurements would be a first step toward a quantification of pore volumes of the constitutive rocks. It could be enhanced by seismic or electrical monitoring to give estimate of the fracture porosity. Beside porosity stand however the question of water movements in the massif, which was not approached here.

Concerning surface processes, a better knowledge of both n-factors requires local daily measurements of air, ground surface and upper ground temperature. This can be achieved by the setting of a low-depth temperature borehole for some years. Furthermore, the n-factor theory of correlation between air and surface seasonal indexes can be contested. The development of a physical-based heat transfer model can be considered.

\subsection{Side implications}

$2 \mathrm{D}$ modelling experiments demonstrated the possible persistence of a fossil permafrost core in the failure slope (fig. 13). The location of this core undoubtedly affects hydrology and mechanics of the landslide.

Meteorology and hydrology definitely influence the dynamics of a landslide. The presence of an impermeable permafrost core avoid circulation of porous water, and therefore helps stabilizing the massif. Moreover, if this core reach the unsaturated zone, its melt is probably associated with the release of large liquid water quantities.

Mechanically, the modelled fossil permafrost core is very probably crossed by the plane of maximum elastic shear stress. One can therefor suggest permafrost to play a stabilization role on this plane. Such processes could be explored by a coupled thermomechanical model.

\section{Conclusion}

A numerical model of deep permafrost evolution was developped. 1D sensibility tests were performed and demonstrated that porosity and ground surface properties are the most influent parameters on thawing dynamics of permafrost. $2 \mathrm{D}$ implementation of the model illustrated the possible persitence of a permafrost core under a deglaciated slope.

The current model can be improved by taking account of mechanical or hydrological processes. However, its application to existing landslides requires a better estimation of involved parameters.

\section{Acknowledgments}

Thanks to Benjamin Causse, Fabien Hubans, JeanFrançois Gamond, Laurent Baillet, Lucile Tatard, Stéphane Schwartz and Thomas Grangeon for interesting discussions, support and help in writing the present report, and violet lemonades! Graphics made with Inkscape and Scilab. Written with LaTeX under Linux Ubuntu and Fedora.

\section{References}

Alley, R. B. (2000). The Younger Dryas cold interval as viewed from central Greenland. Quaternary Science Reviews, 19:213-226.

Alley, R. B. (2004). GISP2 ice core temperature and accumulation data. IGBP PAGES/World Data Center for Paleoclimatology Data Contribution Series \#2004-013. NOAA/NGDC Paleoclimatology Program, Boulder CO, USA.

Arnaud, H., Bravard, Y., Fournier, D., Gidon, M., and Montjuvent, G. (1978). Carte géol. France (1/50 000), feuille Grenoble (772), Orléans: BRGM.

Augustinus, P. C. (1995). Glacial valley cross-profile development: the influence of in situ rock stress and rock mass strength, with examples from the Southern Alps, New Zealand. Geomorphology, 14:87-97. 
Ballantyne, C. K. (2002). Paraglacial geomorphology. Quaternary Science Reviews, 21:1935-2017.

Berest, P., Berthomieu, G., Blanchard, D., Charpentier, J. P., Côme, B., de Bruyn, D., de Marsily, G., Derlich, S., Frémond, M., Ghoreychi, M., Goguel, J., Gonze, P., Guenot, A., Homand, F., Houpert, R., Hueckel, T., Jamet, P., Jouanna, P., Lévy, M., Maury, V., , Millard, A., Staupendahl, A., Tijani, S.-M., Vasseur, G., Vouille, G., and Weber, P. (1988). La thermomécanique des roches. Éditions du BRGM.

Cailleux, A. (1974). Les roches. Que sais-je? Presses Universitaires de France, 7 edition.

Carmichael, R. S. (1984). Handbook of physical properties of rocks, volume 3. CRC Press.

Davis, B., Brewer, S., Stevenson, A., Guiot, J., and data contributors (2003). The temperature of europe during the holocene reconstructed from pollen data. Quaternary Science Reviews, 22:1701-1716.

Delisle, G. (1998). Numerical simulation of permafrost growth and decay. Journal of Quaternary Science, 13(4):325-333.

Duan, X. and Naterer, G. (2009). Heat conduction with seasonal freezing and thawing in an active layer near a tower foundation. International Journal of Heat and Mass Transfer, 52:2068-2078.

Fowler, C. M. R. (2005). The solid Earth. Cambridge University Press, 2 edition.

Gamond, J.-F., Ménard, G., and Schwartz, S. (2008). Etude de la potentialité de risque d'écroulement sur le versant est de la Dent du Loup. Technical report, Pôle Grenoblois Risques Naturels.

Gruber, S. and Haeberli, W. (2007). Permafrost in steep bedrock slopes and its temperature-related destabilization following climate change. Journal of Geophysical Research, 112:F02S18.

Harris, C., Arenson, L. U., Christiansen, H. H., Etzelmüller, B., Frauenfelder, R., Gruber, S., Haeberli, W., Hauck, C., Hölzle, M., Humlum, O.,
Isaksen, K., Kääb, A., Kern-Lütschg, M. A., Lehning, M., Matsuoka, N., Murton, J. B., Nötzli, J., Phillips, M., Ross, N., Seppälä, M., Springman, S. M., and Mühll, D. V. (2009). Permafrost and climate in Europe: Monitoring and modelling thermal, geomorphological and geotechnical responses. Earth-Science Reviews, 92:117-171.

Infoclimat (2009). http://www.infoclimat.fr.

Jorgensen, M. T. and Kreig, R. A. (1988). A model for mapping permafrost distribution based on landscape component maps and climatic variables. In Proceedings of the 5th International Conference on Permafrost, volume 1, pages 176-182, Trondheim, Norway.

Kukkonen, I. and Šafanda, J. (2001). Numerical modelling of permafrost in bedrock in northern Fennoscandia during the Holocene. Global and Planetary Change, 29:259-273.

le Roux, O., Schwartz, S., Gamond, J.-F., Jongmans, D., Bourles, D., Braucher, R., Mahaney, W., Carcaillet, J., and Leanni, L. (2009). CRE dating on the head scarp of a major landslide (Séchilienne, French Alps), age constraints on Holocene kinematics. Earth and Planetary Science Letters, 280:236-245.

Lliboutry, L. (1965). Traité de glaciologie, volume 2. Masson \& Cie, éditeurs.

Lunardini, V.-J. (1978). Theory of n-factors and correlation of data. In Proceedings of the 3rd International Conference on Permafrost, volume 1, pages 40-46, Edmonton, Canada.

Mottaghy, D. and Rath, V. (2006). Latent heat effects in subsurface heat transport modelling and their impact on palaeotemperature reconstructions. Geophysical Journal International, 164:236245 .

Noetzli, J. (2008). Modeling transient threedimensional temperature fields in mountain permafrost. PhD thesis, Universität Zürich. 
Noetzli, J. and Gruber, S. (2008). Transient thermal effects in alpine permafrost. The Cryosphere Discussions, 2:185-224.

Noetzli, J., Gruber, S., and Friedel, S. (2007a). Modeling transient permafrost temperatures below steep alpine topography. In Proceedings of the COMSOL Conference 200\%, pages 139-143, Grenoble, France.

Noetzli, J., Gruber, S., Kohl, T., Salzmann, N., and Haeberli, W. (2007b). Three-dimensional distribution and evolution of permafrost temperatures in idealized high-mountain topography. Journal of Geophysical Research, 112:F02S13.

Peyron, O., Guiot, J., Cheddadi, R., Tarasov, P., Reille, M., de Beaulieu, J.-L., Bottema, S., , and Andrieu, V. (1998). Climatic reconstruction in europe for 18,000 yr B.P. from pollen data. Quaternary Research, 49:183-196.

Ramstein, G., Kageyama, M., Guiot, J., Wu, H., Hély, C., Krinner, G., , and Brewer, S. (2007). How cold was Europe at the Last Glacial Maximum? a synthesis of the progress achieved since the first PMIP model-data comparison. Climate of the Past, 3:331-339.

Riseborough, D., Shiklomanov, N., Etzelmuller, B., Gruber, S., and Marchenko, S. (2008). Recent advances in permafrost modelling. Permafrost and Periglacial Processes, 19:137-156.

Romanovsky, V. E. and Osterkamp, T. E. (2000). Effects of Unfrozen water on heat and mass transport processes in the active layer and permafrot. Permafrost and Periglacial Processes, 11:219-239.

Smith, M. W. and Riseborough, D. W. (1996). Permafrost monitoring and detection of climate change. Permafrost and Periglacial Processes, 7(4):301-309.

Stacey, F. D. and Davis, P. M. (2008). Physics of the Earth. Cambridge University Press, 4 edition.

Wegmann, M., Gudmundsson, G. H., and Haeberli, W. (1998). Permafrost changes in rock walls and the retreat of alpine glaciers: a thermal modelling approach. Permafrost and Periglacial Processes, 9:23-33. 